\title{
Addendum (Erratum)
}

\section{Permanent diabetes mellitus in the first year of life}

\author{
D. Iafusco ${ }^{1}$, M. A. Stazi ${ }^{2}$, R. Cotichini ${ }^{2}$, M. Cotellessa ${ }^{3}$, M. E. Martinucci ${ }^{4}$, M. Mazzella ${ }^{3}$, V. Cherubini ${ }^{5}$, \\ F. Barbetti ${ }^{6}$, M. Martinetti ${ }^{7}$, F. Cerutti ${ }^{8}$, F. Prisco ${ }^{1}$, and the Early Onset Diabetes Study Group \\ of the Italian Society of Paediatric Endocrinology and Diabetology ${ }^{1}$ \\ ${ }^{1}$ Department of Paediatrics, Second University of Naples, Napoli, Italy \\ 2 Department of Epidemiology - Istituto Superiore di Sanità, Rome, Italy \\ ${ }^{3}$ Department of Paediatrics, University of Genoa, G. Gaslini Institute, Genoa, Italy \\ ${ }^{4}$ Regional Center for Juvenile Diabetes, Meyer Paediatric Hospital, Florence, Italy \\ ${ }^{5}$ Department of Paediatrics, University of Ancona, Ancona, Italy \\ ${ }^{6}$ Laboratory of Molecular Endocrinology and Metabolism, IBCIT, Biomedical Scientific Park Rome S. Raffaele, \\ Rome and Bambino Gesù Paediatric Hospital, IRCCS, Rome, Italy \\ ${ }^{7}$ HLA Laboratory, Immunohematology and Transfusion Center, IRCCS Policlinic, Pavia, Italy \\ ${ }^{8}$ Department of Paediatrics, University of Turin, Turin, Italy
}

\section{Diabetologia (2002) 45:798-804}

'The epidemiological result of 33/100 000 cases of Sardinian diabetes is in the article entitled: The Sardinian IDDM study: Epidemiology and geographical distribution of Type I (insulindependent) diabetes mellitus in Sardinia during 1989 to 1994. Songini M, Bernardinelli L, Clayton D, Montomoli C, Pascutto C, Ghislandi M, Fadda D, Bottazzo GF from Diabetologia (1998) 41: 221-227'

Published online: 5 December 2002

C) Springer-Verlag 2002

The online version of the original article can be found at http://dx.doi.org/10.1007/s00125-002-0837-2

Corresponding author: D. Iafusco, Department of Paediatrics, Second University of Naples, Via S. Andrea delle Dame n 4 80100 Napoli, Italy, E-mail: dario.iafusco@unina2.it 